\title{
Why Do Relatives of Patients at the Emergency Room Get Angry? Turkey
}

\author{
Zeynep Karaman Özlü', İbrahim Özlü², Tülay Yıldırım², Ayşegül Çay Yayla', Atıf Bayramoğlu² \\ 'Department of Surgical Nursing, Atatürk University School of Medicine, Erzurum, Turkey \\ ${ }^{2}$ Department of Emergency Medicine, Atatürk University School of Medicine, Erzurum, Turkey
}

\begin{abstract}
Aim: The purpose of this descriptive study was to examine the anger states of the relatives of critically ill patients admitted to the emergency departments and the reasons for these anger states.

Materials and Methods: The study was conducted at the Emergency Department of a University Hospital between September 2013 and January 2014 202 relatives of critically ill patients who matched the inclusion criteria and accepted to participate were included in the study. The "questionnaire," which was prepared by the researcher in line with the literature and involved the demographic characteristics of patient relatives and reasons of their anger at the emergency department, was used as the data collection tool.

Results: It was determined that $29.2 \%$ of the patient relatives were enraged by the emergency department; $18.6 \%$, about the registration procedures; $45.8 \%$, about the treatment duration; $42.4 \%$, about the deficiency of treatment; $13.6 \%$, about the deficiency of medical staff; $3.4 \%$, about the deficiency of the waiting environment; $49.2 \%$, about the lack of information; $39.0 \%$, about the lack of communication; $44.1 \%$, about the irrelevance of the medical staff; and $57.6 \%$, about the waiting time. It was noted that $32.2 \%$ would have decreased anger if the waiting time was reduced.

Conclusion: Summarily, it is considered that making the required explanations to patients/patient relatives, providing large and comfortable recreation places where they can wait, increasing the number of medical staff, and approaching patients with an empathetic attitude will increase the satisfaction of patients/patient relatives, meet their expectations, minimize communication problems, and decrease anger levels.
\end{abstract}

Keywords: Patient relatives, emergency department, rage

\section{Introduction}

Individuals experience a number of feelings like anxiety, excitement, sorrow, pleasure, and fear in the face of various events in their daily lives in the ever developing and complicating world. One of these feelings is anger. Anger is one of the five basic feelings-the others being happiness, sorrow, fear, and hate-that is experienced by a person and is a natural affection for human beings (1-3). Anger is defined as a strong feeling that is related to cognitions appearing against any real or supposed frustration, threat, or injustice, and it prompts the person to remove the disturbing stimulants (4).

One of the areas-probably the most important one-where anger management is crucial is the health sector. It could be asserted that in this sector, the unit being exposed to anger and violence the most often is the emergency unit. Every individual has different ways of expressing their feelings. Disputes experienced between the medical staff and patients/patient relatives are not surprising. Patients usually express their anger either directly or indirectly by rejecting the treatment and care, refusing to cooperate, making frequent demands, verbal bullying or using sarcastic words, and constant complaining. They are mostly unable to explicitly express their anger, and consequently, try to express their anger indirectly as they are dependent on others for their care (5).

Emergency departments are units that provide medical evaluation and treatment for patients that have met with accidents or require emergency intervention. Physicians, nurses, and other medical staff working in this department realize the treatment and care of emergency patients as a team by focusing on specific goals (6). Studies have determined that a majority of patients are admitted to the emergency department because of the following: perceiving

Correspondence to: Zeynep Karaman Özlü e-mail:zynp_krmnzl@hotmail.com 
themselves and their relatives as emergency cases, living close to the emergency department, waiting for a shorter time to be examined, being unable to get in line in relevant polyclinics, demanding prescriptions or reports, and having parenteral practices (7).

Emergency personnel are under constant stress because of the department's environment, excessive number of patients to be taken care of, patient deaths, sleep disorders, and intensive work schedules (8). Patients and patient relatives, on the other hand, usually have fear and anxiety because they do not know what to do. They expect emergency intervention as they consider their condition more urgent than the other patients, and society has not adopted the necessity for triage yet. This usually causes disputes between the emergency staff and patients/patient relatives.

This study was conducted in order to determine the anger states of the relatives of critically ill patients admitted to the emergency department and the reasons for these anger states.

\section{Materials and Methods}

\section{Study design}

This descriptive and cross-sectional study was conducted in order to examine the anger states of the relatives of critically ill patients admitted to the emergency department and the reasons for these anger states.

\section{Time and place of the study}

This study involved 202 relatives of critically ill patients at the Emergency Department of the Ataturk University Research Hospital from September 3, 2013 to January 30, 2014.

\section{Population and sample group of the study}

While the population of the study consisted of all the relatives of critically ill patients who applied to the Emergency Department of the Ataturk University Research Hospital between the specified dates, the sample group consisted of 202 relatives of critically ill patients who applied to the emergency clinic between the specified dates, met the inclusion criteria, and accepted to participate in the study.

Because the needs of the relatives of patients, who were followed-up for more than 24 hours at the emergency department, could change (Redley B, Beanland), the data of the study were collected by interviewing with patient relatives that met the inclusion criteria at the emergency department and attended on patient, who was followed up at the emergency department, within the first 24 hours.

\section{Inclusion criteria of the study:}

$>$ Being a relative of the patient admitted to the emergency department and meeting the emergency and serious criteria,

$>$ Being older than 18,

$>$ Having no previous or present psychiatric problems.

\section{Data collection}

\section{Data collection tools}

Being developed by the researcher in line with literature and consisting of a single part, the questionnaire included questions regarding the demographic characteristics of patient relatives, emergency department, and anger reasons of patient relatives in the emergency department.

\section{Data collection method}

The patient relatives who participated in the study were informed about the objective of the study and that the information would not be used anywhere other than the study, and their verbal consents were received. The study data were collected by the researcher conducting a face-to-face interview with the patient relatives within the first $24 \mathrm{~h}$ after being admitted to the hospital. The data collection process took approximately 8-10 $\mathrm{min}$ for each person.

\section{Data assessment}

The study data were analyzed using the Statistical Package for the Social Sciences (SPSS Inc.; Chicago, IL, USA) version 16.0. Percentage distribution, mean, and chi-square tests were used to assess the data. In the comparison of the groups in terms of independent variables, variance was used for the data exhibiting a normal distribution and the Mann-Whitney $U$ test and Kruskal-Wallis test were used for the data exhibiting no analysis distribution. While examining the intergroup difference, 0.05 was used as the significance level. A significant intergroup difference was indicated as $p<0.05$ and no significant intergroup difference as $\mathrm{p}>0.05$.

\section{Ethical principles of the study}

An ethical committee approval was received from the Health Sciences Faculty of Ataturk University in order to conduct the study; further, official permission was taken by presenting an information form describing the objective and scope of the study to the Head Physician of the Erzurum Ataturk University Research Hospital in order to implement the study. Since the use of human phenomenon in studies requires the protection of personal rights, the patient relatives were verbally informed about the objective of the study. They were told that their personal information would be protected after being shared with the researcher and that the acquired information and identity of the answerer would be kept confidential. They were allowed to withdraw from the study at any time. Thus, verbal permissions from the patient relatives were received by fulfilling the ethical principles of "Informed Consent," "Autonomy," and "Confidentiality and the Protection of Confidentiality."

\section{Generalizability of the study}

The results obtained from the study could be generalized to the relatives of critically ill patients coming to the Emergency Department of Ataturk University Research Hospital, however they could be also used in studies conducted in different emergency departments.

\section{Results}

By examining the descriptive characteristics of patient relatives that were included in the study (Table 1), it was determined that $38.7 \%$ of the patient relatives were in the age range of 38 years and above; $54.5 \%$, female; $44.6 \%$, high school graduates; $29.7 \%$, civil servants or housewives; $46.5 \%$, insured by the Social Insurance Institution; and $42.3 \%$, children of the patients based on their affinity with the patient.

Table 2 illustrates the distribution of the characteristics of patients and patient relatives with regard to the emergency department. Evidently, $44.6 \%$ of the patient relatives came to the emergency department between $08: 01$ and $16: 00,86.6 \%$ of the patient 
Table 1. Distribution of descriptive characteristics of patient relatives

\begin{tabular}{|c|c|c|}
\hline Characteristics & Number & Percentage \\
\hline \multicolumn{3}{|l|}{ Age Group } \\
\hline $18-27$ years & 64 & 31.6 \\
\hline $28-37$ years & 60 & 29.7 \\
\hline 38 years and older & 78 & 38.7 \\
\hline \multicolumn{3}{|l|}{ Gender } \\
\hline Female & 110 & 54.5 \\
\hline Male & 92 & 45.5 \\
\hline \multicolumn{3}{|l|}{ Education } \\
\hline Primary School & 57 & 28.2 \\
\hline High School & 90 & 44.6 \\
\hline University & 55 & 27.2 \\
\hline \multicolumn{3}{|l|}{ Occupation } \\
\hline Housewife & 60 & 29.7 \\
\hline Civil servant & 60 & 29.7 \\
\hline Worker & 34 & 16.8 \\
\hline Student & 25 & 12.4 \\
\hline Craftsman & 17 & 8.4 \\
\hline Retiree & 6 & 3.0 \\
\hline \multicolumn{3}{|l|}{ Health Insurance of the Patient: } \\
\hline Social Insurance Institution & 94 & 46.5 \\
\hline Retirement fund & 52 & 25.7 \\
\hline $\begin{array}{l}\text { Social security organization for } \\
\text { artisans and the self-employed }\end{array}$ & 29 & 14.4 \\
\hline Green Card & 27 & 13.4 \\
\hline \multicolumn{3}{|l|}{ Affinity with the Patient } \\
\hline Spouse & 31 & 15.2 \\
\hline Child & 85 & 42.3 \\
\hline Parent & 16 & 7.9 \\
\hline Sibling & 20 & 9.9 \\
\hline Friend & 14 & 6.9 \\
\hline Relative & 36 & 17.8 \\
\hline Total & 202 & 100 \\
\hline
\end{tabular}

relatives came with the patient, $21.3 \%$ of the patients had a cardiovascular complaint, $52.4 \%$ of the patients were transferred to the relevant department, and $21.8 \%$ of the patients were admitted because of a trauma/accident.

Table 3 illustrates that $45.8 \%$ of the patient relatives were enraged about the treatment duration; $42.4 \%$, about deficiency of treatment; $49.2 \%$, about lack of information; 39.0\%, about lack of communication; $44.1 \%$, about irrelevance of the medical staff; and $57.6 \%$, about the waiting time. It was observed that $32.2 \%$ of the patient relatives would have decreased anger if the waiting times were reduced.
Table 2. Distribution of characteristics of patients and patient relatives with regard to the emergency department

\begin{tabular}{|l|c|c|}
\hline Features & Number & Percentag \\
\hline \multicolumn{2}{|l|}{ Arrival time in the emergency department } \\
\hline 08:01-16:00 & 90 & 44.6 \\
\hline 16:01-24:00 & 57 & 28.2 \\
\hline 24:01-08:00 & 55 & 27.2 \\
\hline
\end{tabular}

State of coming to the emergency department

\begin{tabular}{|l|c|c|}
\hline With the patient & 175 & 86.6 \\
\hline After the patient & 27 & 18.4 \\
\hline
\end{tabular}

\section{Patient's complaint}

Cardiovascular system

Trauma-accident

Respiratory system

Neurologic diseases

Suicide

Gastrointestinal system

General condition deterioration

\begin{tabular}{|l|l|l|}
\hline 43 & 21.3 \\
\hline 41 & 20.8 \\
\hline 40 & 19.8 \\
\hline 31 & 15.3 \\
\hline 17 & 8.4 \\
\hline 16 & 7.9 \\
\hline 14 & 6.9 \\
\hline
\end{tabular}

Unit where the patient was transferred to

\begin{tabular}{|l|c|c|}
\hline Hospitalized to relevant service & 106 & 52.4 \\
\hline Intensive care & 42 & 20.8 \\
\hline Discharged to home & 27 & 13.4 \\
\hline Those who were not transferred & 27 & 13.4 \\
\hline
\end{tabular}

Patient's diagnosis

\begin{tabular}{|l|l|l|}
\hline Trauma-accident & 44 & 21.8 \\
\hline Cardiovascular system & 43 & 21.3 \\
\hline Respiratory system & 38 & 18.8 \\
\hline Poisoning & 26 & 12.9 \\
\hline Hematologic-oncologic diseases & 20 & 9.9 \\
\hline Neurologic diseases & 17 & 8.4 \\
\hline Endocrine system diseases & 9 & 4.5 \\
\hline Gastrointestinal system & 5 & 2.4 \\
\hline
\end{tabular}

\section{Discussion}

Anger is frequently experienced between the patients/patient relatives and the medical staff in emergency departments (9). Patient relatives have close feelings with the patients with regard to their psychological state and become angry and anxious unless an effort is made to understand their feelings and they are respected. The presence of angry patient relatives may subject the medical staff to violence (10).

It is indicated that patients and patient relatives may occasionally have an increased level of anger toward emergency services personnel, which may result in violence (11-13). In these studies, the patient relatives experiencing anger were determined to be in the age range of 18-27 years, male, and university graduates. The studies 
Table 3. Distribution of characteristics of patient relatives with regard to the state of rage

\begin{tabular}{|l|c|c|}
\hline State of raging in the emergency service \\
\hline Yes & 59 & 29.2 \\
\hline No & 143 & 70.8 \\
\hline State of raging about registration procedures (n=59) \\
\hline Yes & 11 & 18.6 \\
\hline No & 48 & 81.4 \\
\hline State of raging about treatment duration (n=59) \\
\hline Yes & 27 & 45.8 \\
\hline No & 32 & 54.2 \\
\hline State of raging about deficiency of treatment (n=59) \\
\hline Yes & 25 & 42.4 \\
\hline No & 34 & 57.6 \\
\hline State of raging about deficiency of medical staff (n=59) \\
\hline Yes & 8 & 13.6 \\
\hline No & 51 & 86.4 \\
\hline
\end{tabular}

State of raging about deficiency of the waiting environment $(\mathbf{n}=59)$

\begin{tabular}{|l|c|c|}
\hline Yes & 2 & 3.4 \\
\hline No & 57 & 96.6 \\
\hline
\end{tabular}

State of raging about lack of information $(n=59)$

\begin{tabular}{|l|c|c|}
\hline Yes & 29 & 49.2 \\
\hline No & 30 & 50.8 \\
\hline \multicolumn{3}{|c|}{ State of raging about lack of communication (n=59) } \\
\hline Yes & 23 & 39.0 \\
\hline No & 36 & 61.0 \\
\hline
\end{tabular}

State of raging about irrelevance of medical staff $(n=59)$

\begin{tabular}{|l|l|l|}
\hline Yes & 26 & 44.1 \\
\hline No & 33 & 55.9 \\
\hline
\end{tabular}

State of raging about waiting duration $(n=59)$

\begin{tabular}{|l|l|l|}
\hline Yes & 34 & 57.6 \\
\hline No & 25 & 42.4 \\
\hline
\end{tabular}

What to do to remove the anger $(n=59)$

\begin{tabular}{|l|c|c|}
\hline Reduce the durations of waiting & 19 & 32.2 \\
\hline $\begin{array}{l}\text { Make sufficient explanations/reduce } \\
\text { the waiting duration /train the medical } \\
\text { staff about communication }\end{array}$ & 15 & 25.4 \\
\hline Make sufficient explanations & 9 & 15.3 \\
\hline $\begin{array}{l}\text { Train the medical staff about } \\
\text { communication Reduce the durations } \\
\text { of waiting/increase the number of } \\
\begin{array}{l}\text { medical staff/train the medical staff } \\
\text { about communication }\end{array}\end{array}$ & 6 & 13.6 \\
\hline Increase the number of medical staff & 2 & 3.4 \\
\hline
\end{tabular}

also determined that enraged patients/patient relatives were male and younger when compared to those who were not enraged (14, 15). In the study conducted by Erkol et al. (16), it was determined that the patient relatives had particularly greater anger than patients: men aged between 21 and 30 years had higher levels of anger and greater inclination toward violence. The result of this study shows a similarity with the studies of Dolan et al. (14), Mellesdal (15), Erkol et al. (16), and Ketelsen et al. (17). In the study conducted by Raja and Azzoni (18), they determined that there was no difference between the educational backgrounds of enraged patients/patient relatives. In this study, on the other hand, university graduates were observed to have greater anger. This may be due to the fact that university graduates requested to get information about their patients from the medical staff more frequently, and consequently, had higher levels of expectations. The emergency departments generally have the greatest density of patients between 16:00 and 20:00, and it is observed that patients/patient relatives have higher levels of anger and violence during these hours (19). In this study, it was observed that patient relatives had higher levels of anger between 16:00 and 24:00, which is similar to the results of the study of Lau (19). This situation can be associated with excessive intensity of patients at the emergency rooms during evening hours, and therefore, increased anger levels of the patient relatives. It is indicated that patients/patient relatives have higher levels of anger and violence and this is frequently experienced in the field of healthcare services, particularly in emergency departments (20). In this study, $29.2 \%$ of the patients were enraged. Similar to this result, the study of Ayranci et al. (12) showed that acts of violence were experienced at a higher rate at the emergency departments, which caused the patients to experience higher levels of anger.

At emergency departments, patient relatives may get enraged because of the deficiency of treatment or intervention, resulting in violence $(21,22)$. In line with the literature, $42.4 \%$ patients were enraged due to the deficiency of treatment in this study.

This study revealed that $49.2 \%$ patients were enraged about the lack of information. Medical personnel working at the emergency department may consider everything in the department as routine. However, nothing is routine for patients as well as their families. Patient families request kindness, good care, confidence, cleanliness, and consideration toward their personal interests from the emergency department team. Therefore, it should be ensured that families are involved in patient care, and they should be given the necessary information and explanations (23).

It was determined that $39.0 \%$ patients were enraged about the lack of communication. Similar to this result, in the study conducted by Hahn et al. (24), the failure of sustaining a relationship with different patients/patient relatives increased the level of anger and caused violence.

It is indicated that existing problems of anxious patients and patient relatives in emergency units, as well as the longer waiting times and delays caused by a number of reasons, may cause them to lose patience and lead to an increase in their anger levels. This may result in the display of aggressive tendencies (21). In this study, $57.9 \%$ patients were enraged about long waiting times, too. Patients and patient relatives expect the identification and solution of their problems as soon as possible during extensively stressful situations. Increases in the waiting times due to various reasons may cause the patients and patient relatives to experience increased stress, the ex- 
pectations of medical staff can gradually change, and the communication process becomes more problematic. In their study, Boz et al. (25) stated that longer waiting times increased the anger levels of patients/patient relatives, leading them to exhibit violence toward the medical staff.

Similar to the reasons of anger stated in this study, the following facts increase the anger levels of patients/patient relatives and cause medical staff to be exposed to violence. Patient relatives request to be immediately taken care of and they think that their patients are more urgent, waiting rooms are untidy and crowded, registration procedures take a long time, patients and patient relatives have suspicions about the irregular business or injustice regarding inclusions, number of medical staff is insufficient during the busiest time of the day, and the staff displays irrelevance $(10,17,19,22,23,25)$.

As a consequence, it is assumed that making the necessary explanations to the patients/patient relatives, providing them with large and comfortable recreation places where they can wait, allowing them to see their patients after certain intervals, facilitating the bureaucratic procedures, increasing the number of medical staff, and making the medical staff approach the patients with an empathetic attitude will increase the satisfaction of the patients/patient relatives admitted to emergency services, meet their expectations, minimize communication problems with patients/patient relatives at the emergency services, and decrease the levels of anger.

\section{Study Limitations}

The limitations of this study are that every patient applying to the emergency clinic due to increased patient flow was not included in the study, and the results of the study could be generalized only to the institution where the study was conducted.

Ethics Committee Approval: Ethics committee approval was received for this study from the ethics committee of Ataturk University School of Medicine (Decision No: 10/05/2013).

Informed Consent: Verbal informed consent was obtained from patients' parents who participated in this study.

Peer-review: Externally peer-reviewed.

Conflict of Interest: No conflict of interest was declared by the authors.

Financial Disclosure: The authors declared that this study has received no financial support.

\section{References}

1. Albertı R, Emmons M. Assertiveness use your right. 1st ed. HYB Publications Ankara, 1998. p.107-123.

2. Kısaç Ş. University students of anger and anger expression levels of according to some variables. Institute of Social Sciences, Department of Educational Sciences, Hacettepe Univ. 1997.
3. Üstün B, Yavuzarslan F. The Power of Anger. J Hacettepe University School Nursing 1995; 2: 42-6.

4. Balkaya F, Sahin NH. Multidimensional anger scale. Turk Psikiyatri Derg 2003; 14: 192-202.

5. Terakye G. Nurse Patient Relations. 5th ed., Ankara, Summit Offset Ltd. Co., 1998.

6. Şen S, Yorulmaz H, Batmaz M. Emergency department in the burnout syndrome. 5tf National Nursing Students Congress, Congress Book 2007; April 20-21, Şanlıurfa.

7. Bulut $\mathrm{H}$. Emergency department in the patients and their relatives impact on the satisfaction of informing. J Emerg Surg Trauma 2006; 12: 28898.

8. Cevik AA, Holliman CJ, Yanturali S. Emergency physicians and "burn out" syndrome. Ulus Travma Acil Cerrahi Derg 2003; 9: 85-9.

9. Arik $C$, Anat $R$, Arie E. Encountering anger in the emergency department: identification, evaluations and responses of staff members to anger displays. Emerg Med Int 2012; 2012: 603215. [CrossRef]

10. Altıntas, N. Determination Violence Towards Nurses in Health Care Settings. Istanbul University, Institute of Health Science, Department Of Psychiatry Nursing. Master Thesis. Istanbul. 2006.

11. Hahn S, Hantikainen V, Needham I, Kok G, Dassen T, Halfens RJ. Patient and visitor violence in the general hospital, occurrence, staff interventions and consequences: a cross-sectional survey. J Adv Nurs 2012; 68: 2685-99. [CrossRef]

12. Ayranci U, Yenilmez C, Balci Y, Kaptanoglu C. Identification of violence in Turkish health care settings. J Interpers Violence 2006; 21:276-96. [CrossRef]

13. Ayranci $U$. Violence toward health care workers in emergency departments in west Turkey. J Emerg Med 2005; 28: 361-5. [CrossRef]

14. Dolan M, Fullam R, Logan C, Davies G. The Violence Risk Scale Second Edition (VRS-2) as a predictor of institutional violence in a British forensic inpatient sample. Psychiatry Res 2008; 158: 55-65. [CrossRef]

15. Mellesdal L. Aggression on a psychiatric acute ward: a three-year prospective study. Psychol Rep 2003; 92: 1229-48. [CrossRef]

16. Erkol H, Gökdoğan MR, Erkol Z, Boz B. Aggression and violence towards health care providers--a problem in Turkey? J Forensic Leg Med 2007; 14 423-8. [CrossRef]

17. Ketelsen R, Zechert C, Driessen M, Schulz M. Characteristics of aggression in a German psychiatric hopsital and predictors of patients at risk. J Psychiatr Ment Health Nurs 2007; 14: 92-9. [CrossRef]

18. Raja M, Azzoni A. Hostility and violence of acute psychiatric inpatients. Clin Pract Epidemiol Ment Health 2005; 1: 11. [CrossRef]

19. Lau J, Magarey J, McCutcheon H. Violence in the emergency department: a literature review. J Aust Emerg Nurs 2004; 7: 27-37. [CrossRef]

20. Vural F, Çiftçi S, Fil Ş, Dura A, Vural B. A state hospital for emergency service workers violence: The frequency of reports of violence. J Turk Family Practice 2013; 17: 147-52.

21. Sucu G, Cebeci F, Karazeybek E. Emergency services working to violence by patients and their relatives. J Turk Emerg Med 2007; 7: 156-62.

22. Al B, Zengin S, Derhal Y, Gökçen C, Yılmaz DA, Yıldırım C. Increased violence towards health care staff. Eurasian J Emerg Med 2012; 11: 115-24.

23. Gürlek Ö. Patient families emergency services and expectations from emergency service nurses. Surgical Nursing Department, Afyon Kocatepe University, 2005.

24. Hahn S, Zeller A, Needham I, Kok G, Dassen T, Halfens RJG. Patient and visitor violence in general hospitals: a systematic review of the literature. Aggr Viol Behav 2008; 13: 431-41. [CrossRef]

25. Boz B, Acar K, Ergin A, Erdur B, Kurtuluş A, Turkcuer I, et al. Violence toward health care workers in emergency departments in Denizli, Turkey. Adv Ther 2006; 23: 364-9. [CrossRef] 